\title{
Pattern and Determinants of Antiretroviral Drug Adherence among Nigerian Pregnant Women
}

\author{
S. O. Ekama, ${ }^{1}$ E. C. Herbertson, ${ }^{1}$ E. J. Addeh, ${ }^{1}$ C. V. Gab-Okafor, ${ }^{1}$ \\ D. I. Onwujekwe, ${ }^{1}$ F. Tayo, ${ }^{2}$ and O. C. Ezechi ${ }^{1}$ \\ ${ }^{1}$ Clinical Sciences Division, Nigerian Institute of Medical Research, P.M.B 2013, Yaba, Lagos, Nigeria \\ ${ }^{2}$ Department of Clinical and Biopharmacy, Faculty of Pharmacy, University of Lagos, P.M.B 12003, Surulere, Lagos, Nigeria
}

Correspondence should be addressed to S. O. Ekama, sozichu@yahoo.com

Received 4 August 2011; Revised 24 November 2011; Accepted 9 December 2011

Academic Editor: Karen Odberg-Petterson

Copyright ( 12012 S. O. Ekama et al. This is an open access article distributed under the Creative Commons Attribution License, which permits unrestricted use, distribution, and reproduction in any medium, provided the original work is properly cited.

\begin{abstract}
Background. The need for a high level of adherence to antiretroviral drugs has remained a major hurdle to achieving maximal benefit from its use in pregnancy. This study was designed to determine the level of adherence and identify factors that influence adherence during pregnancy. Method. This is a cross-sectional study utilizing a semistructured questionnaire. Bivariate and multiple logistic regression models were used to determine factors independently associated with good drug adherence during pregnancy. Result. $137(80.6 \%)$ of the interviewed 170 women achieved adherence level of $\geq 95 \%$ using 3 day recall. The desire to protect the unborn child was the greatest motivation (51.8\%) for good adherence. Fear of being identified as HIV positive (63.6\%) was the most common reason for nonadherence. Marital status, disclosure of HIV status, good knowledge of ART, and having a treatment supporter were found to be significantly associated with good adherence at bivariate analysis. However, after controlling for confounders, only HIV status disclosure and having a treatment partner retained their association with good adherence. Conclusion. Disclosure of HIV status and having treatment support are associated with good adherence. Maternal desire to protect the child was the greatest motivator for adherence.
\end{abstract}

\section{Introduction}

The introduction of highly active antiretroviral therapy (HAART) has not only improved longevity in HIV-infected individuals but in addition has had a significant impact on the rate of mother-to-child transmission of HIV infection (MTCT) [1]. Mother-to-child transmission is one of the modes of HIV transmission. Vaginal delivery contributes 60 $70 \%$ of MTCT, breastfeeding contributes $20-30 \%$, while inutero infection could occur in less than 10\% of MTCT [2]. Without preventive intervention, about $25-40 \%$ of infants born to HIV-positive mothers will contract the virus [2]. Following introduction of HAART, the rates of mother-tochild transmission of HIV infection has practically crashed to less than $2 \%[3,4]$. However, the success of HAART, like any medication, is dependent on both the intrinsic properties of the drugs and the individual's ability to take the medication as prescribed [5]. This is particularly true in the prevention of mother-to-child transmission, where the consequence of failing to achieve viral suppression is the transmission of the virus to the baby [5]. Adequate adherence to the prescribed antiretroviral medications is essential to achieving maximal viral suppression necessary to prevent MTCT [4].

Adherence rates exceeding 95\% are necessary, in order to maximize the benefits of antiretroviral therapy. Higher levels of drug adherence are associated with improved virological, immunological, and clinical outcome [6].

Poor adherence to antiretroviral drugs during pregnancy can lead to suboptimal viral suppression, development of viral resistance, higher risk of mother-to-child transmission, and mother-to-child transmission of resistant HIV strains [5].

Interrupting medication permits the virus to resume rapid replication and as many as $10^{10}$ viral particles will be produced per day [7].

This allows resistant mutant strains to be generated which are no longer responsive to available antiretroviral drugs, posing a public health danger [7].

Adherence to antiretroviral drugs poses unique challenges to HIV infected persons particularly in pregnant women 
[7]. Improving adherence among pregnant women therefore requires knowledge of the factors that influence adherence.

Several methods have been used to measure adherence, but no gold standard has been established [8]. Each of these methods has its respective strengths and weaknesses. Available methods include pill counts, self-report, prescription refills, medication event monitoring system (MEMS), biological markers, and assays $[4,9]$.

Though several studies in Nigeria have evaluated the factors associated with nonadherence to antiretroviral therapy among HIV-positive adults [10-12], only one from literature search studied antiretroviral adherence issues in HIV-positive pregnant women [4].

They deduced from their study that the determinants of nonadherence to antiretroviral drugs in HIV-positive pregnant women were low level of education, nondisclosure of HIV status, and longer duration of therapy [4].

Good adherence is imperative for the success of PMTCT. This study, therefore, seeks to find out if there is good adherence to antiretroviral drugs among HIV-positive pregnant women.

The main objective of this study is to determine the level and factors that influence adherence to antiretroviral drugs among HIV-positive pregnant women accessing PMTCT services in Lagos Nigeria.

\section{Research Questions}

(1) What is the level of adherence to antiretroviral drugs among pregnant women?

(2) What are the barriers to adherence in pregnancy?

(3) What factors facilitate adherence among pregnant women?

\section{Method}

2.1. Study Setting. The study was conducted at the HIV treatment Centre of the Nigerian Institute of Medical Research (NIMR), Lagos, a Federal Government of Nigeria Comprehensive HIV Care and Treatment Centre. NIMR is supported by AIDS Prevention Initiative in Nigeria (APIN) through the United States president's emergency fund for AIDS relief (PEPFAR), funding since 2004. The Centre provides an outpatient Prevention of Mother-To-Child-Transmission of HIV Infection (PMTCT) services, in addition to adult and pediatric HIV services. Pregnant women who tested positive to HIV are referred from the NIMR HIV counseling and testing centre or other public and private health institutions to the PMTCT clinic which takes place once a week, on Wednesdays. Intrapartum care is provided for these women in collaboration with some hospitals within Lagos metropolis which include Lagos University Teaching Hospital Idi Araba, Lagos State University Teaching Hospital Ikeja, General Hospital Surulere, General Hospital Apapa, General Hospital Ikorodu, Havana Specialist Hospital Surulere, and Rao Specialist Hospital Surulere. Antenatal, postnatal, and infant post exposure prophylaxes are provided by NIMR. Health workers from the collaborating centres have been trained on intrapartum care of HIV-positive mothers both by NIMR and the national HIV programme. Each woman on the PMTCT programme is referred to any of the collaborating centres, close to their place of residence at 36 weeks or as soon as possible for late booking. The referral note usually contains detailed information about their chosen mode of delivery, infant feeding choice, client's Viral Load, and CD4 count. Infant postexposure prophylaxis drugs and mother's antiretroviral drugs are given to the women on referral. The women are sent back to the centre at 2 weeks postdelivery with a completed Case Record Form (CRF) designed specifically to capture all delivery-related information. Information on the CRF is used to complete the postnatal data base. The Home-Based Care Team contacts any of the women who did not report back 2 weeks after the expected date of delivery. This is to ascertain the reasons for the default.

2.2. Study Design. This is a cross-sectional study that was carried out between 1st September 2009 and 31st November 2009. A semistructured questionnaire was administered to the women who met the inclusion criteria and gave consent to participate in the study. Knowledge of ART was measured by asking some basic questions, which were graded. A score above $70 \%$ was classified good while below 70\% was not good. Adherence was measured by expressing the number of doses taken as a percentage of the number of doses prescribed. For example if 20 doses are prescribed and 19 doses are taken, adherence is 95\% [13].

2.3. Study Population. All pregnant women with known gestational age either by date or early ultrasound seen during the study period and who gave informed consent were enrolled. At the time of the conduct of the study, a total of 273 pregnant HIV-positive women were registered for PMTCT services. The study aimed for a precision of $\pm 5 \%$ for a proportion of $50 \%$ using $95 \%$ confidence interval, therefore, a sample size of 70 subjects was required. In order to increase the power of the study, we decided to enroll all pregnant HIVpositive women who attended PMTCT clinic between 1st September and 31st November 2009 provided the minimum sample size of 70 is met.

2.4. Data Management. The enrolled women were interviewed using a semistructured questionnaire containing closed and open-ended questions. The open-ended questions were included to give the women opportunity to freely express themselves without boxing them into closed answers. Information on demographics, socioeconomic characteristics, knowledge of HIV, and antiretroviral drug medication, adherence pattern, reasons for missing drugs, and factors that encourage adherence were also contained in the questionnaire. Data management was with SPSS for windows version 17 . The $P$ value was based on $95 \%$ confidence intervals (CI); a $P$ value $>0.05$ was not significant (NS).

Descriptive analyses were first performed followed by bivariate analyses of the determinant factors associated with good adherence. The variables that were found significant at this level were added to a multivariate logistic regression model and those with a $P$-value $<0.05$ were considered 
significant in the final multivariate model, calculating odds ratios $(\mathrm{OR})$ and $95 \%$ confidence interval $(\mathrm{CI})$.

2.5. Ethical Issues. Ethical approval for the study was obtained from the Institutional Review Board, Nigerian Institute of Medical Research, Lagos, Nigeria. Written informed consent was obtained from all women for the use of their data for study however, women who declined consent to participate in study were provided care but excluded from research.

The clinic patients are organized into an independent support group of people living with HIV (Positive Life Organization of Nigeria) that ensures that patients are not stigmatized and discriminated against. This group ensures that no patient is denied requisite care because of failure to participate in any of our studies including this study.

\section{Results}

During the three months study period, one hundred and seventy eligible HIV-positive pregnant women consented and were interviewed. One hundred and thirty seven $(80.6 \%)$ of the interviewed women reported achieving adherence level of greater or equal to $95 \%$ using 3 day recall method, with a nonadherent rate of $19.4 \%$.

The sociodemographic characteristics of the respondents are shown in Table 1. Majority of the women were aged $30-34$ years $(52.4 \%)$, married $(77.1 \%)$, have at least one living child (70.0\%), employed/working (76.5\%), had at least secondary education $(81.1 \%)$, and from the three major ethnic tribes of Yoruba, Igbo, and Hausa (84.1\%).

Pregnancy and HIV-related characteristics are summarized in Table 2. One hundred and forty seven (86.5\%) women had disclosed their HIV status and their disclosure was to their partners in most of the cases (97.3\%). The majority of the women were on first line HAART regimen $(58.2 \%)$, while the rest of the women were either on nonHAART prophylactic regimen $(24.7 \%)$ or 2 nd line HAART regimen $(17.1 \%)$. Only $20.0 \%$ and $22.9 \%$ of the women have had previous PMTCT experience and were within the first trimester, respectively. Their knowledge of HIV and antiretroviral therapy were very good as over $85 \%$ of the respondent had very good knowledge. The use of treatment support was relatively common as greater than half of the women had a treatment supporter (55.9\%) who is the husband in $89.5 \%$ of the cases.

The outcome of subanalysis of reasons given for adhering to the antiretroviral drugs as prescribed, among the women that had adherence level greater 95\%, is shown in Table 3. The desire to ensure that the unborn child is protected from HIV infection was the greatest motivation (51.8\%). Some of the written expression of the women, expressing the desire to protect the child as the motivation for adherence includes "I want to protect my baby," "I do not want to live with the guilt of infecting my baby," and "I learnt my baby will not be infected if I take my drugs religiously." The desire to remain healthy and alive was the other motivator for adhering to the ARV drugs (21.2\%). These are some of the respondents' written expression "I want to live long train my children and fulfill my
TABLE 1: The sociodemographic characteristics of the women enrolled in the study.

\begin{tabular}{lc}
\hline Characteristics & Number of women (\%) \\
& $N=170$ \\
\hline Age (years) & $2(1.2)$ \\
(i) $<20$ & $20(11.8)$ \\
(ii) $20-24$ & $43(25.3)$ \\
(iii) $25-29$ & $89(52.4)$ \\
(iv) $30-34$ & $13(7.6)$ \\
(v) $35-39$ & $3(1.8)$ \\
(vi) $\geq 40$ & \\
Number of living children & $51(30.0)$ \\
(i) 0 & $67(39.4)$ \\
(ii) $1-2$ & $52(30.6)$ \\
(iii) $>2$ & \\
Marital status & $131(77.1)$ \\
(i) Married & $39(22.9)$ \\
(ii) Not married & \\
Occupation & $35(20.6)$ \\
(i) Housewife & $5(2.9)$ \\
(ii) Unemployed & $130(76.5)$ \\
(iii) Employed/Working & \\
Educational level completed & $3(1.8)$ \\
(i) No formal education & $29(17.1)$ \\
(ii) primary & $99(58.2)$ \\
(iii) Secondary & $39(22.9)$ \\
(iv) Tertiary & \\
Ethnic group & $78(45.9)$ \\
(i) Yoruba & $52(30.6)$ \\
(ii) Igbo & $13(7.6)$ \\
(iii) Hausa & \\
(iv) Other tribes & \\
\hline & \\
& \\
&
\end{tabular}

life dreams," "To keep me healthy, as I was always on admission in the hospital before I started treatment. I am now okay since I started the ARV drugs."

The reasons given by the nonadherent respondents for missing or skipping their drugs are shown in Table 4. Forgetfulness $(57.6 \%)$, tight work schedule $(39.4 \%)$, and fear of being identified as HIV positive $(63.6 \%)$ were the common reasons for skipping or missing drugs among the nonadherent women. The respondents expressed this in written form, for example, "I get stuck in traffic sometimes on my way home from work and am not comfortable carrying my drugs around or taking them in the public."

Table 5 shows the bivariate analysis of some possible factors associated with good drug adherence. Of the nine variables, only four variables which are marital status $(P=$ $0.023)$, disclosure of HIV status $(P=0.000)$, good knowledge of HIV, and ART ( $P=0.001$ and having a treatment supporter (0.002) were found to be significantly associated with good adherence. However, after subjecting the variables found to be significantly associated with good adherence to multiple logistic regressions while controlling for other 
TABLE 2: The distribution of pregnancy and HIV related characteristics of the women enrolled in the study.

\begin{tabular}{lc}
\hline Characteristics & $\begin{array}{c}\text { Number of women (\%) } \\
N=170\end{array}$ \\
\hline HIV status disclosure & $147(86.5)$ \\
(i) Disclosed & $23(13.5)$ \\
(ii) Not disclosed & \\
ARV drug regimen & $42(24.7)$ \\
(i) Mono and Dual therapy & $99(58.2)$ \\
(ii) First line HAART & $29(17.1)$ \\
(iii) 2nd line HAART & \\
Gestational age (weeks) & $39(22.9)$ \\
(i) Less than 13 & $52(30.6)$ \\
(ii) 13-28 & $79(46.5)$ \\
(iii) Greater or equal to 29 & \\
Previous PMTCT experience & $34(20.0)$ \\
(i) Yes & $136(80.0)$ \\
(ii) No & \\
Knowledge of HIV and ART & $146(85.9)$ \\
(i) Good & $24(14.1)$ \\
(ii) Poor & \\
Has treatment supporter & $95(55.9)$ \\
Yes & $75(44.1)$ \\
No &
\end{tabular}

TABLE 3: Reason for adherence to ARV drugs among respondents with over $95 \%$ drug adherence.

\begin{tabular}{lc}
\hline Reason for Adherence & No of respondents $(\%)^{*}$ \\
\hline To protect my unborn child & $71(51.8)$ \\
To stay healthy and alive & $29(21.2)$ \\
As I was told by counselors & $27(19.7)$ \\
Informed by my previous & $16(11.7)$ \\
PMTCT experience & \\
${ }^{*}$ No of respondents greater than 137 because of multiple responses.
\end{tabular}

TABLE 4: Reasons for missing drugs among the 33 respondents that had less than $95 \%$ adherence.

\begin{tabular}{lc}
\hline Reason for nonadherence & No of respondents $(\%)^{*}$ \\
\hline Forgetfulness & $19(57.6)$ \\
Slept off & $11(33.3)$ \\
Work schedule & $13(39.4)$ \\
Religious activity & $9(27.3)$ \\
Food requirement of the drug & $7(21.2)$ \\
Afraid of someone identifying & $21(63.6)$ \\
\hline
\end{tabular}

${ }^{*}$ No of respondents greater than 33 because of multiple responses.

potential confounders, only HIV status disclosure (odds ratios: 6.1; CI: 2.8-11.6) and having a treatment partner (odds ratios: 2.5 ; CI: $1.3-6.7$ ) retained their association with good adherence.

\section{Discussion}

Effective strategies to reduce mother-to-child transmission of HIV infection are well known and well established $[1,3]$. These include the use of ARV drugs, avoiding unplanned and unwanted pregnancy in HIV-positive women, safe delivery and infant feeding options, reduction of unwarranted and unnecessary surgical intervention during pregnancy and labor, prevention of prolonged rupture of membrane, and so forth $[1,3]$. Research has also shown that at undetectable viral load, it is possible to achieve zero mother to child transmission of HIV infection [1]. Antiretroviral drugs can only achieve the required effect at adherence level of at least 95\% [14]. Poor adherence to antiretroviral drugs has been reported to be the major challenge to achieving the goal of antiretroviral therapy [15]. Many factors have been cited as reasons for nonadherence in HIV-positive adults [10-12, 1518 ], but relatively few adherence studies have been done in HIV positive pregnant women [4, 19]. Apart from factors preventing adherence in nonpregnant adults, the nausea and vomiting of pregnancy and possible effect of the drugs on the fetus are additional factors that makes adherence in pregnancy a challenge.

We conducted this study not only to provide this scarce information on adherence in pregnancy but also to generate information that will assist during adherence counseling for pregnant HIV positive women accessing PMTCT services.

The nonadherence rate of $19.4 \%$ among our cohort, though comparable to $21.7 \%$ reported by Igwegbe et al. in South Eastern Nigeria is much lower than 37.1\% and $37.4 \%$ reported by Olowookere et al. [10] and Shaahu et al. [11], respectively, from Southwestern Nigeria where present study was conducted. Considering that our study and that of Igwegbe et al. [4] was among pregnant women unlike the two studies by Olowookere et al. [10] and Shaahu et al. [11], it seems that adherence is better in pregnancy. It is not surprising that women are willing and ready to do anything, to ensure the wellbeing of their offspring. The above statement was confirmed in this study in which $51.8 \%$ of the adherent women gave the reason of protecting their unborn child from HIV infection as the major motivator for taking their drug as prescribed. The effect of vomiting and nausea of pregnancy was not noticed in this study, as majority of the women are referred patients after HIV diagnosis. At the time, these women present to NIMR HIV treatment centre, the nausea and vomiting of pregnancy would have subsided.

The free services offered at NIMR, compared to other centres, may have played a great role, as cost of drugs and laboratory services have been shown to be a major barrier to antiretroviral drug adherence $[18,20]$. The adherence rate of $99 \%$ reported by Jones and Barthlomew [19] among 194 pregnant women where services were completely free gives credence to this assertion. The adherence level of $99 \%$ reported above also showed that we need to do a lot of work on issues of adherence. Presently, all patients are counseled prior to the initiation of antiretroviral therapy, but there is need to reevaluate counseling methods and techniques 
TABLE 5: Factors associated with good adherence among the respondents.

\begin{tabular}{|c|c|c|c|c|}
\hline Factors & $\begin{array}{l}\text { Adherent respondents (\%) } \\
\qquad N=137\end{array}$ & $\begin{array}{l}\text { Nonadherent respondents } \\
\text { (\%) } N=33\end{array}$ & OR $(95 \% \mathrm{CI})$ & $P$ value \\
\hline \multicolumn{5}{|l|}{ Age (years) } \\
\hline (i) $<20$ & $2(1.5)$ & 0 & 1.00 & \\
\hline (ii) $20-35$ & $123(89.8)$ & $28(84.9)$ & 1.00 & \\
\hline (iii) $\geq 35$ & $12(8.8)$ & $5(15.1)$ & $2.56(0.85-7.85)$ & 0.08 \\
\hline \multicolumn{5}{|l|}{ Number of living children } \\
\hline (i) 0 & $42(30.7)$ & $9(27.3)$ & $0.82(0.28-2.44)$ & 0.88 \\
\hline (ii) $1-2$ & $57(41.6)$ & $10(30.3)$ & 1.00 & \\
\hline (iii) $>2$ & $38(27.7)$ & $14(42.4)$ & $2.10(0.78-5.75)$ & 0.17 \\
\hline \multicolumn{5}{|l|}{ Marital status } \\
\hline (i) Married & $119(86.9)$ & $12(36.4)$ & $(1.13-6.79)$ & 0.23 \\
\hline (ii) Not married & $18(13.1)$ & $21(63.6)$ & 1.00 & \\
\hline \multicolumn{5}{|l|}{ Occupation } \\
\hline (i) Unemployed & $28(20.4)$ & $12(36.4)$ & 1.00 & \\
\hline (ii) Employed/Working & $109(79.6)$ & $21(63.6)$ & $0.45(0.18-1.11)$ & 0.09 \\
\hline \multicolumn{5}{|l|}{$\begin{array}{l}\text { Educational level } \\
\text { completed }\end{array}$} \\
\hline (i) Less than secondary & $26(19.0)$ & $6(18.2)$ & 1.00 & \\
\hline (ii) At least Secondary & $111(81.0)$ & $27(81.8)$ & $1.05(0.36-3.18)$ & 0.89 \\
\hline \multicolumn{5}{|l|}{ HIV status disclosure } \\
\hline (i) Disclosed & $131(95.6)$ & $16(48.5)$ & $(3.06-23.6)$ & 0.000 \\
\hline (ii) Not disclosed & $6(4.4)$ & $17(51.5)$ & 1.00 & \\
\hline \multicolumn{5}{|l|}{$\begin{array}{l}\text { Previous PMTCT } \\
\text { experience }\end{array}$} \\
\hline (i) Yes & $31(22.6)$ & $3(9.0)$ & $2.92(0.78-12.92)$ & 0.13 \\
\hline (ii) No & $106(77.4)$ & $30(91.0)$ & 1.00 & \\
\hline \multicolumn{5}{|l|}{$\begin{array}{l}\text { Knowledge of HIV and } \\
\text { ART }\end{array}$} \\
\hline (i) Good & $124(90.5)$ & $22(66.7)$ & $4.77(1.73-13.22)$ & 0.001 \\
\hline (ii) Poor & $13(9.5)$ & $11(33.3)$ & 1.00 & \\
\hline \multicolumn{5}{|l|}{ Has treatment supporter } \\
\hline Yes & $85(62.0)$ & $10(30.3)$ & $3.76(1.55-9.26)$ & 0.002 \\
\hline No & $52(38.0)$ & $23(69.7)$ & 1.00 & \\
\hline
\end{tabular}

where necessary, aiming to achieve the $99 \%$ adherence level reported by Jones and Barthlomew [19].

Encouraging the women to come along with a treatment supporter for the counseling sessions prior to initiation of antiretroviral therapy preferably the partners would help in educating the partners appropriately and improving adherence in the long run.

Apart from reviewing the counseling techniques, the knowledge of the adherence counselors also needs to be evaluated as their beliefs and attitudes are central to effective counseling.

Among the nonadherent women, similar reasons reported in other studies for missing drugs were found [4, 10, $11,18]$. It, therefore, shows that pregnancy related factors are not the reasons for missing antiretroviral drugs during pregnancy, but as a result of other personal and sociocultural factors. Stigma and discrimination remain an important factor militating against quality HIV care, as $63.6 \%$ of women in this study expressed the reason for missing their drugs as afraid of being identified as HIV positive. There is, therefore, the need for continued campaign against stigma and discrimination if we must improve adherence to antiretroviral drugs and uptake of other HIV-related services.

The findings of HIV status disclosure and having a treatment support as factors associated with good adherence after controlling for potential confounders is in agreement with previous studies [8]. With the disclosure of HIV status to partners, who in most cases is the husband, he will not only provide support but will act as treatment partner for the spouse. We, therefore, need to encourage these women, to disclose their status to get the maximal benefit of disclosure. It is important, however, to note that women should not be forced to disclose their status, as HIV status disclosure has been reported to be accompanied by partner violence [21]. 
Instead women who decline to disclose should be counseled and encouraged until they feel safe to disclose.

It is important to state that self-report used to measure adherence is not the gold standard for adherence measurement, but it has been reported to be sufficient enough to assess adherence when pill count is not possible and electronic devices and blood ARV blood measurement are not feasible [15].

\section{Conclusion}

In conclusion, this study has shown that good adherence is achievable during pregnancy, however, more has to be done to achieve adherence rate of $99 \%$ reported elsewhere. The identified reasons for nonadherence and the effects of status disclosure and having a treatment partner will be used to improve adherence counseling process.

\section{References}

[1] J. I. Ikechebelu, J. O. Ugboaja, S. O. Kalu, and D. O. Igboelina, "Outcome of prevention of mother to child transmission (PMTCT) of HIV infection programme in Nnewi, Southeast Nigeria," in Proceedings of the 43rd Annual General Meeting and Scientific Conference of the Society of Gynaecology and Obstetrics of Nigeria held in Kano, Novmber 2009.

[2] N. Abdulsalami and O. Tekena, "The epidemiology of HIV/AIDS in Nigeria," in AIDS in Nigeria: A Nation on the Threshold, O. Adeyi, P. Kanki, O. Odutolu, and J. Idoko, Eds., Havard Center for Population and Development Studies, Cambridge, Mass, USA, 2006.

[3] J. Homsy, D. Moore, A. Barasa et al., "Mother-to child HIV transmission and infant mortality among women receiving highly active antiretroviral therapy (HAART) in rural Uganda (abstract TUPE0354)," in Proceedings of the XVI International AIDS Conference, Toronto, Canada, August 2006.

[4] A. O. Igwegbe, J. O. Ugboaja, and L. A. Nwajiaku, "Prevalence and determinants of non-adherence to antiretroviral therapy among HIV- positive pregnant women in Nnewi, Nigeria," International Journal of Medicine and Medical Sciences, vol. 2, no. 8, pp. 238-245, 2010.

[5] L. Hayman, "Adherence to antiretrovirals among us women during and after pregnancy," MCN The American Journal of Maternal/Child Nursing, vol. 34, no. 1, p. 69, 2009.

[6] D. A. Murphy, K. J. Roberts, D. J. Martin, W. Marelich, and D. Hoffman, "Barriers to antiretroviral adherence among HIVinfected adults," AIDS Patient Care and STDs, vol. 14, no. 1, pp. 47-58, 2000.

[7] N. B. Palmer, "Special group—drug use, mental illness, pregnancy," in Medication Adherence in HIV/AIDS, L. Jeffrey, Ed., Liebert, Larchmont, NY, USA, 2004.

[8] J. B. Nachega, A. R. Knowlton, A. Deluca et al., "Treatment supporter to improve adherence to antiretroviral therapy in HIV-infected South African adults: a qualitative study," Journal of Acquired Immune Deficiency Syndromes, vol. 43, supplement 1, pp. S127-S133, 2006.

[9] W. L. Holzemer, I. B. Corless, K. M. Nokes et al., "Predictors of self-reported adherence in persons living with HIV disease," AIDS Patient Care and STDs, vol. 13, no. 3, pp. 185-197, 1999.

[10] S. A. Olowookere, A. A. Fatiregun, J. O. Akinyemi, A. E. Bamgboye, and G. K. Osagbemi, "Prevalence and determinants of non adherence to highly active antiretroviral therapy among people living with HIV/AIDS in Ibadan, Nigeria," The Journal of Infection in Developing Countries, vol. 2, no. 5, pp. 369-372, 2008.

[11] V. N. Shaahu, T. O. Lawoyin, and A. O. Sangowawa, "Adherence to highly active antiretroviral therapy (HAAT) at a federal medical centre," African Journal of Medicine and Medical Sciences, vol. 37, no. 1, pp. 29-36, 2008.

[12] Z. Iliyasu, M. Kabir, I. S. Abubakar, M. Babashani, and Z. A. Zubair, "Compliance to antiretroviral therapy among AIDS patients in aminu kano teaching hospital, Kano, Nigeria," Nigerian Journal of Medicine, vol. 14, no. 3, pp. 290-294, 2005.

[13] Federal ministry of Health, Nigeria, National guideline for HIV and AIDS treatment and care in adolescents and adults, 2007.

[14] E. O. Idigbe, T. A. Adewole, G. Eisen et al., "Management of HIV-1 infection with a combination of nevirapine, stavudine, and lamivudine: a preliminary report on the Nigerian antiretroviral program," Journal of Acquired Immune Deficiency Syndromes, vol. 40, no. 1, pp. 65-69, 2005.

[15] O. Ezechi, D. Onwujekwe, N. Odunnukwe et al., "Selfreported adherence to HAART is a reliable and cost effective tool in low resource setting," in Proceedings of the 3rd International AIDS Society Conference on HIV Pathogensis, Treatment and Prevention, July 2005, Abstract No. WePe12.7C35.

[16] J. A. Bartlett, "Addressing the challenges of adherence," Journal of Acquired Immune Deficiency Syndromes, vol. 29, supplement 1, pp. S2-S10, 2002.

[17] K. A. Gebo, J. Keruly, and R. D. Moore, "Association of social stress, illicit drug use, and health beliefs with nonadherence to antiretroviral therapy," Journal of General Internal Medicine, vol. 18, no. 2, pp. 104-111, 2003.

[18] E. Markos, A. Worku, and G. Davey, "Adherence to ART in PLWHA at Yirgalem Hospital, South Ethiopia. Ethiop," Journal of Health \& Development, vol. 22, no. 2, pp. 174-179, 2008.

[19] A. Jones and C. Barthlomew, "Adherence to antiretroviral therapy in pregnant woment at an HIV treatment clinic," in Proceedings of the 3rd International AIDS Society Conference on HIV Pathogensis, Treatment and Prevention, Port of Spain Trinidad, July 2005, Abstract No. TuPe 5.5p18.

[20] J Day, N. Godoka, P. Nyamafeni et al., "Adherence to ART in clinical trial settings in Zimbabwe and Uganda: lessons learned," in Proceedings of the International AIDS Conference, Bangkok, Thailand, July 2002.

[21] O. C. Ezechi, C. Gab-Okafor, D. I. Onwujekwe, R. A. Adu, E. Amadi, and E. Herbertson, "Intimate partner violence and correlates in pregnant HIV positive Nigerians," Archives of Gynecology and Obstetrics, vol. 280, no. 5, pp. 745-752, 2009. 


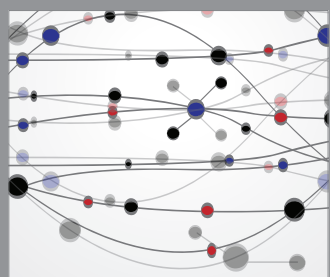

The Scientific World Journal
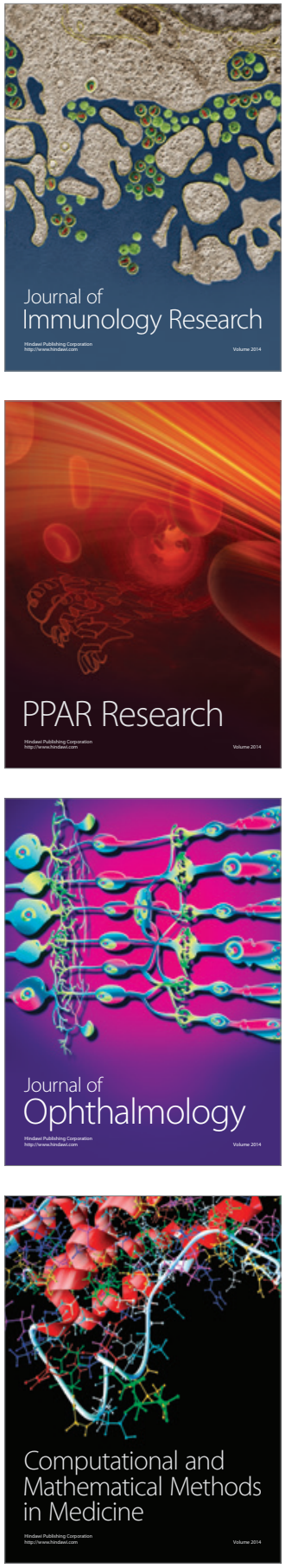

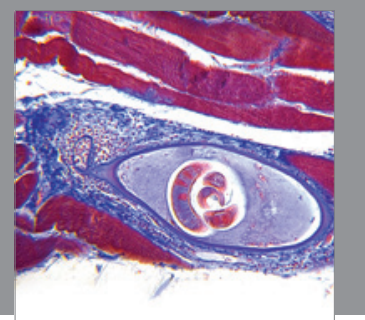

Gastroenterology

Research and Practice
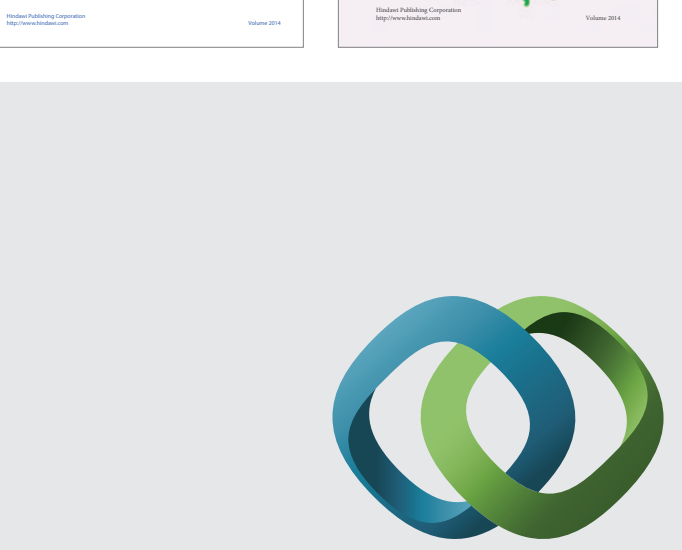

\section{Hindawi}

Submit your manuscripts at

http://www.hindawi.com
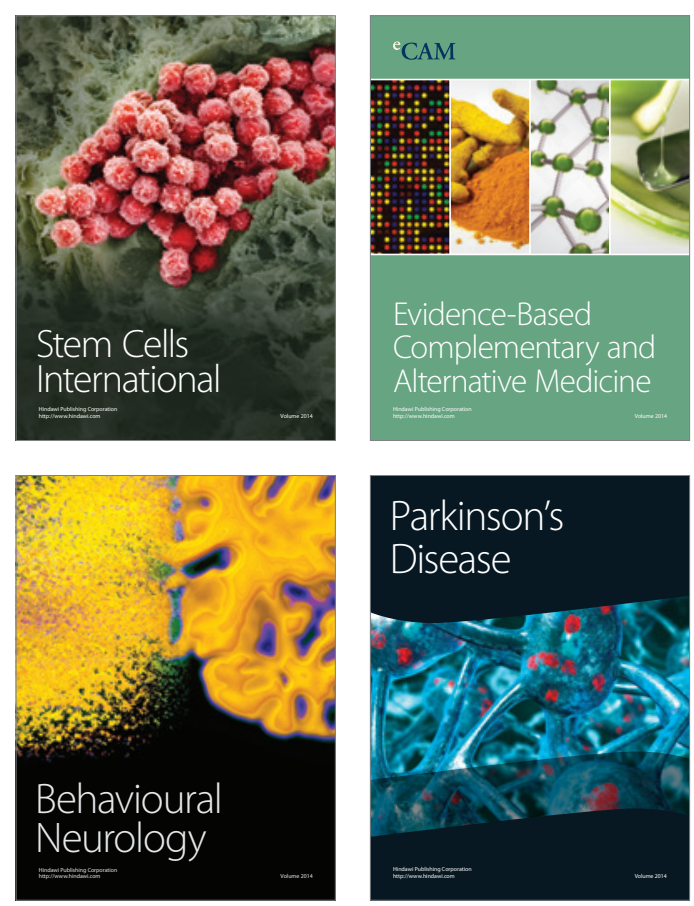

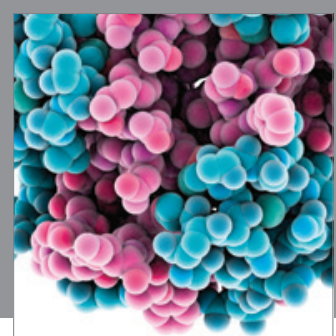

Journal of
Diabetes Research

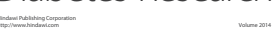

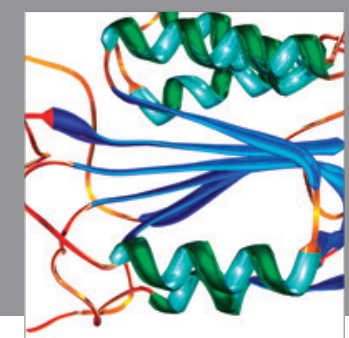

Disease Markers
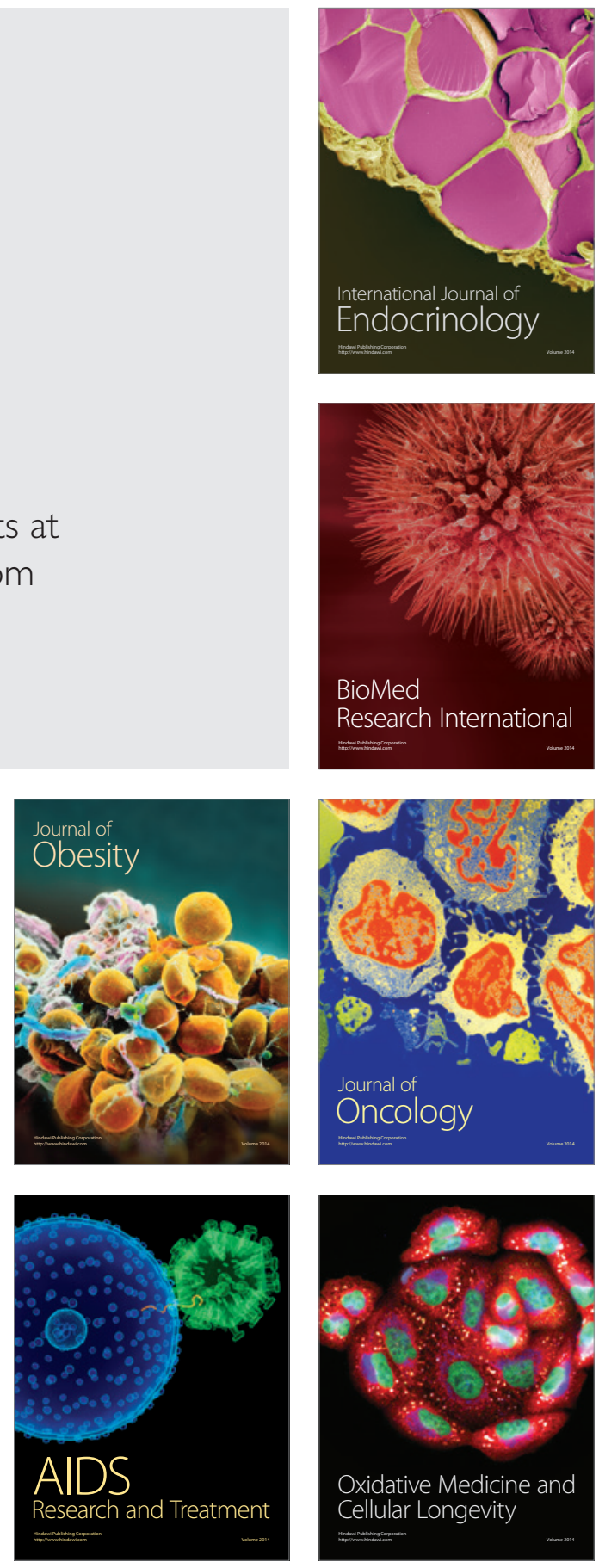